\title{
Ultra rapid strength development in dry-mix shotcrete for ultra rapid support in challenging mining conditions
}

\author{
J-D Lemay Université Laval, Canada \\ M Jolin Université Laval, Canada \\ R Gagné Université de Sherbrooke, Canada
}

\begin{abstract}
Recent development in the field of cementing materials has brought forward many non-traditional binder systems. Engineers involved in the fields of emergency repairs and rapid ground support have been on the lookout for materials that allow rapid production, placement and, most of all, very rapid strength development kinetics. One binder system that fits the description is composed of ordinary Portland cement $(O P C)$, calcium aluminate cement (CAC) and calcium sulfate (C\$). However, this type of binder also sometimes exhibits difficult workability that severely limits its use in regular cast in-place concrete. This limitation is overcome when using dry-mix shotcrete as a placement method, since the contact between water and cement occurs in the nozzle immediately before placement, workability problem are avoided.

As a part of a graduate project at Laval University, 49 different mixes, including simple, binary and (mainly) ternary blends, were tested. Two majors parameters were studied, the development of compressive strength and the volumetric stability. The numerous binder compositions tested allowed the selection of a stable optimised formulation in regard of early compressive strength and volumetric stability. Finally, the selected formulation was successfully tested with industrial dry-mix shotcrete equipment to verify the large scale placement feasibility of such a product.
\end{abstract}

\section{Introduction}

Transport and placement methods for concrete have evolved tremendously throughout history. Although cast-in place concrete is still the most common placement method, other processes have been developed; let us simply think of the first concrete pump, self-levelling concrete or roller compacter concretes. There is also another concrete placement process developed at the beginning of the last century that has gained global acceptance. First presented to the construction industry in 1910 by Carl Akeley (American Concrete Institute $[\mathrm{ACl}] \mathrm{2005)}$, shotcrete is nowadays present everywhere, particularly in the mining and tunnelling businesses.

Shotcrete (also known as sprayed concrete in many parts of the world) is a placement method for concrete. Shotcrete is defined as a mortar or concrete pneumatically projected at high velocity onto a surface (ACl 2005). The high velocity is essential to the process as it ensures an adequate compaction or consolidation and allows the material to stick to the sprayed surface. Without the proper compaction, quality shotcrete cannot be produce ( $\mathrm{ACl} 2009$ ).

As any placement methods, different advantages of shotcrete make it more appropriate in certain situations. With its capacity to stick to vertical and overhead surfaces, shotcrete need only minimum, if any, formworks. To take full advantage of this specificity, shotcrete is best used in ground supports (tunnel, mine, slope stabilisation, etc.), overhead civil work reparation (bridge deck and parking lower surface, etc.) and where complex formworks make cast-in place concrete very expensive (ark type bridge, circular column repairs, etc.). 
Shotcrete can be produce using two different processes, the wet-mix and the dry-mix. The major differences between these processes are the conveying method of the material through the hose and the location where the water is added to the mixture.

\subsection{Wet-mix shotcrete}

In the wet-mix process, all the ingredients are mixed together before being pumped through the hose. Air is added at the nozzle, through an air-ring, to propel the material at high velocity onto the surface ensuring sufficient compaction. As all components are mixed together prior to pumping, wet-mix concrete is usually delivered on site by standard ready-mix truck and is feed directly into the pump.

With the exception of the set-accelerator, all admixtures are blended before pumping. When needed, the set-accelerator is added at the nozzle thought a separate valve by using a special admixture pump. Normal dosage of accelerator usually ranges from $2.5-6 \%$ but dosage of $>10 \%$ of binder content is sometime used (Prudêncio Jr. 1998). Accelerator dosage has to be carefully planned as it reduces long-term resistance and durability of concrete (Neville 2008).

\subsection{Dry-mix shotcrete}

Dry-mix shotcrete is fundamentally different from its wet-mix counterpart. In this process, all the solid materials (gravel, sand, cement, additives, fibres, admixtures) are transported through the hose using compressed air. Water is added through a water ring at the nozzle or shortly before depending on the type of nozzle used. No matter the type of equipment used, the water-binder contact comes only a fraction of a second before placement. This particularity enables this process to bypass workability issues usually associated with the mixing and pumping of regular concrete. Figure 1 shows a schematic of a typical dry-mix shotcrete setup.

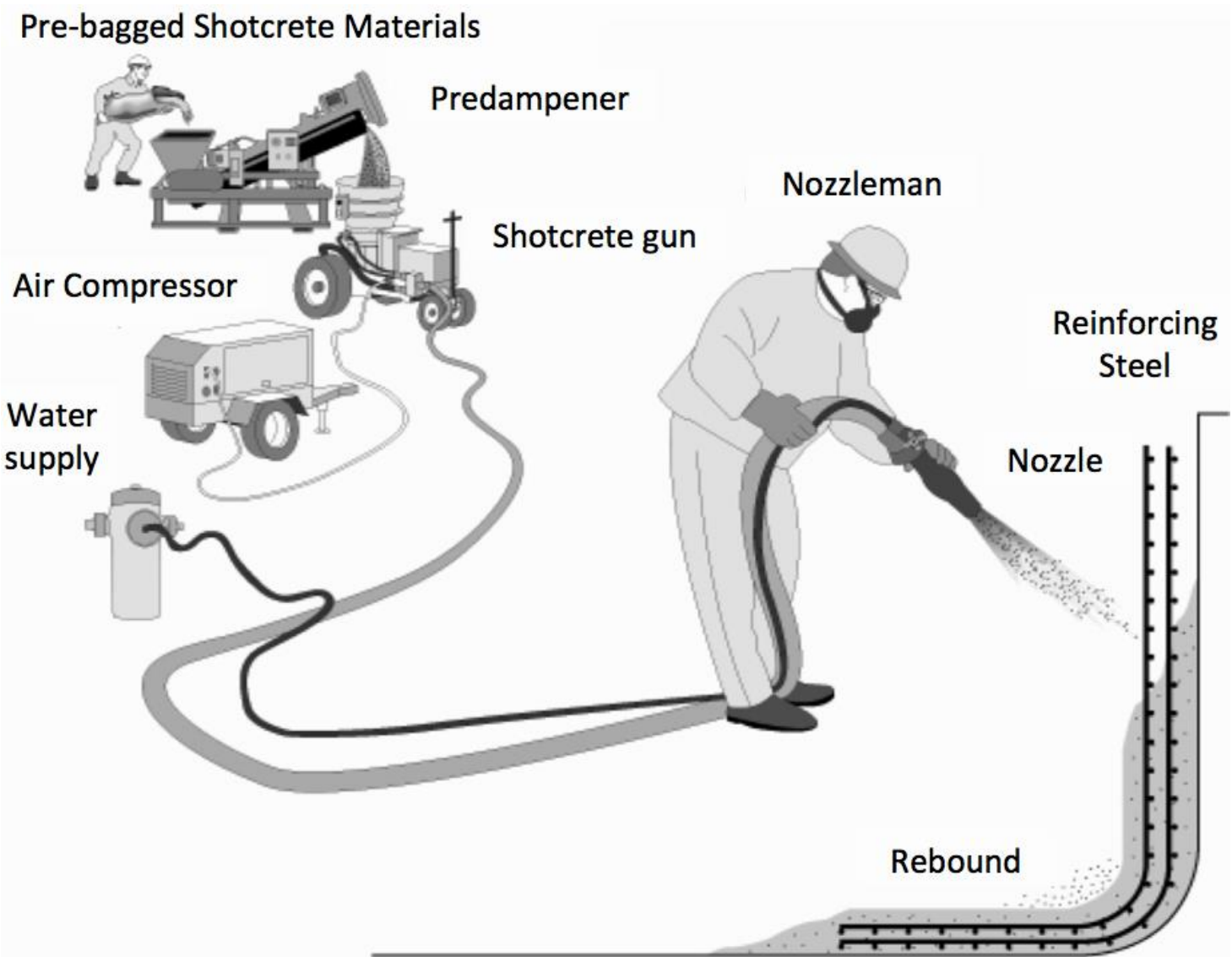

Figure 1 Typical setup for dry-mix shotcrete operations 
Since materials are introduced in the dry state in the hose, production of dry-mix shotcrete usually takes advantage of pre-bagged material. This enables easier quality control of the material as the production of such bags is done in a controlled environment.

\subsection{Comparison of both process}

Each process have its own advantages and inconvenient. Wet-mix shotcrete is usually used only when high volumes of shotcrete are needed due to the important mobilisation needs. On the other hand, while the dry-mix process cannot reach the production rates of the wet-mix process, its mobilisation costs, preparation time and flexibility are key factors in its selection.

Table 1 presents the major differences between both processes.

Table 1 Difference between dry-mix and wet-mix process

\begin{tabular}{|c|c|}
\hline Dry-mix process & Wet-mix process \\
\hline \multicolumn{2}{|l|}{ Pros } \\
\hline $\begin{array}{l}\text { Instantaneous adjustment of shooting } \\
\text { consistency }\end{array}$ & Known w/cm \\
\hline Delivery hose lighter to move & Rebound and dust are lower \\
\hline Start-stop operations simple & High volume output \\
\hline \multicolumn{2}{|l|}{ Cons } \\
\hline Higher rebound & $\begin{array}{l}\text { High volume output sometimes } \\
\text { difficult to manage }\end{array}$ \\
\hline Low volume output & $\begin{array}{c}\text { Use (and dosage) of accelerator } \\
\text { on site }\end{array}$ \\
\hline
\end{tabular}

\subsection{Development of new shotcrete}

The development of new and alternative binder to Portland cement has opened the field of cementitious binder to a whole new variety of binder. One of those binders exhibiting very promising property is a binder composed of OPC, CAC and C\$ (Lamberet 2005). This type of mixture shows very rapid hardening behaviour but is unfortunately often accompanied with important workability issues. With a pot life of less than 10 minutes, regular cast-in place application of this type of concrete is impossible without the use of numerous chemical admixtures to control set and fluidity. A means to avoid this type of problem was sought and this is where dry-mix shotcrete becomes a very interesting process since water is added only a fraction of a second before impact onto the receiving surface, avoiding workability issues. The validity of such a hypothesis was as part of a research project at Laval University (Lemay 2013).

\section{Research programme}

The research programme was divided in two phases. The first part focuses on the mixture composition and the second on an actual life-size equipment testing.

\subsection{Phase 1}

Ternary binder made of OPC, CAC and C\$ can present expansion if the mix design is not properly done. The expansion can be such as to ruin the concrete (or shotcrete) and so, must be correctly assessed.

Based on work previously conducted by Lamberet (Lamberet 2005), numerous mixture formulations were tested. The stability was evaluated using standard $50 \mathrm{~mm}$ cubes incorporating only fine aggregate (sand). Each mixture had the same proportions and the same W:CM ratio. To ensure sufficient workability for 
casting, a polycarboxylate high range water reducer - superplasticiser was used. The admixture dosage varied based on the formulation as the efficiency was influenced by the major component of the binder (OPC or CAC). Table 2 presents the mix design proportions (by weight) used in Phase 1.

Table 2 Mix design for Phase 1 mixture

\begin{tabular}{ccc}
\hline Water (\%) & Paste (\%) & Aggregate (\%) \\
\hline 7.7 & 17.5 & 74.4
\end{tabular}

The difference between each mixture was the proportion of OPC, CAC and C\$ of the paste. All cubes were cured in a $100 \%$ relative humidity room at $21^{\circ} \mathrm{C} \pm 1^{\circ} \mathrm{C}$. Forms were removed as soon as possible and depending of the setting of the mixture could be as soon as $2 \mathrm{~h}$.

\section{$2.2 \quad$ Phase 2}

The main objective of the project consisted in realising a conventional dry-mix shooting session of a special mixture based on a ternary binder using standard dry-mix equipment and techniques $(\mathrm{ACl} 2005$, 2009). To ensure consistent shotcreting and adequate quality control, the shotcreting took place at Laval University's shotcrete laboratory. The laboratory is equipped with full-scale shotcreting equipment in an indoor environment that is temperature controlled. The shotcrete was sprayed using a rotating barrel

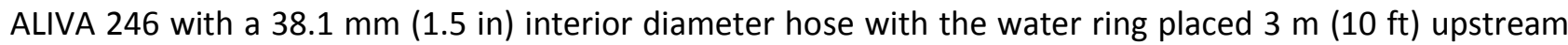
from the outlet of the nozzle - also known as the hydromix nozzle (Figure 2).

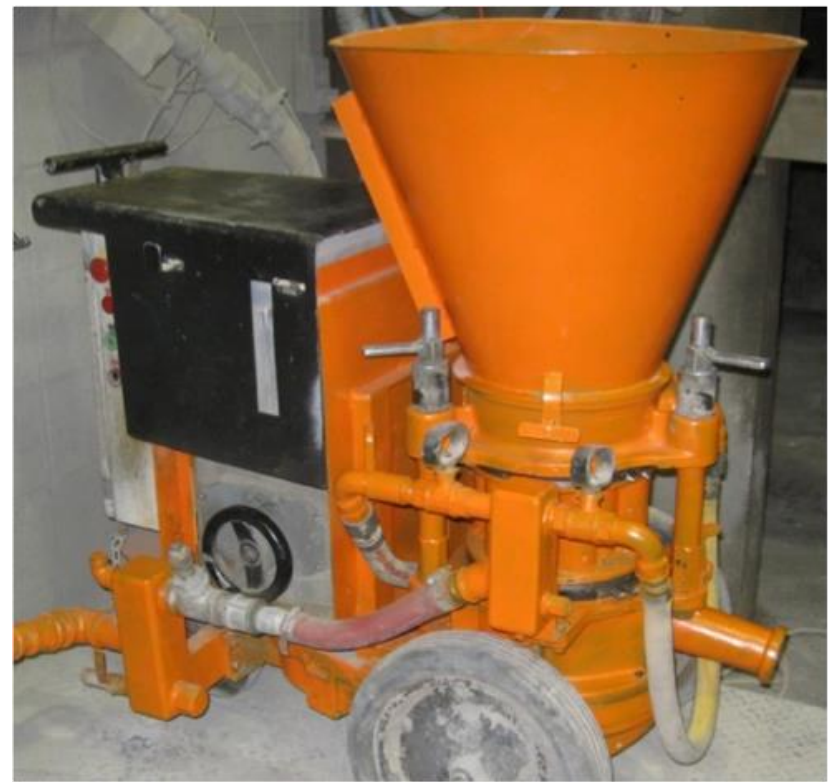

(a)

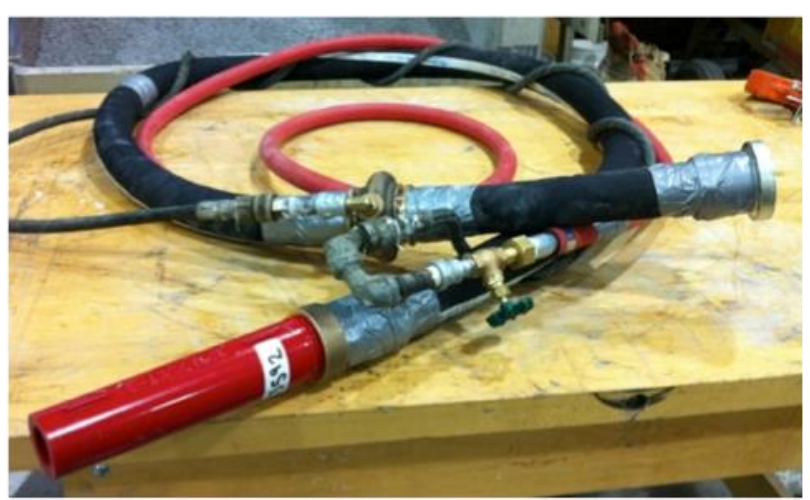

(b)

Figure 2 (a) spraying gun; and (b) hydromix nozzle

The mixture was shot indoors at an average temperature of $21^{\circ} \mathrm{C}\left(70^{\circ} \mathrm{F}\right)$. The shotcrete laboratory's equipment includes an electronic air flow meter, a water flow meter and a set of electronic scales; the data acquisition system records the airflow, the water flow and the material used during the spraying operations (Figure 3). The targeted airflow is $4.25 \mathrm{~m}^{3} / \mathrm{min}$ (180 CFM) at a working air pressure of $700 \mathrm{kPa}$ (100 psi). The water flow was adjusted (by the operator holding the nozzle) to what is referred to in the industry as the wettest stable consistency. The evolution of the water and material flows are used as a quality control point. Irregular or non-uniform flows lead to the rejection of a mixture. 


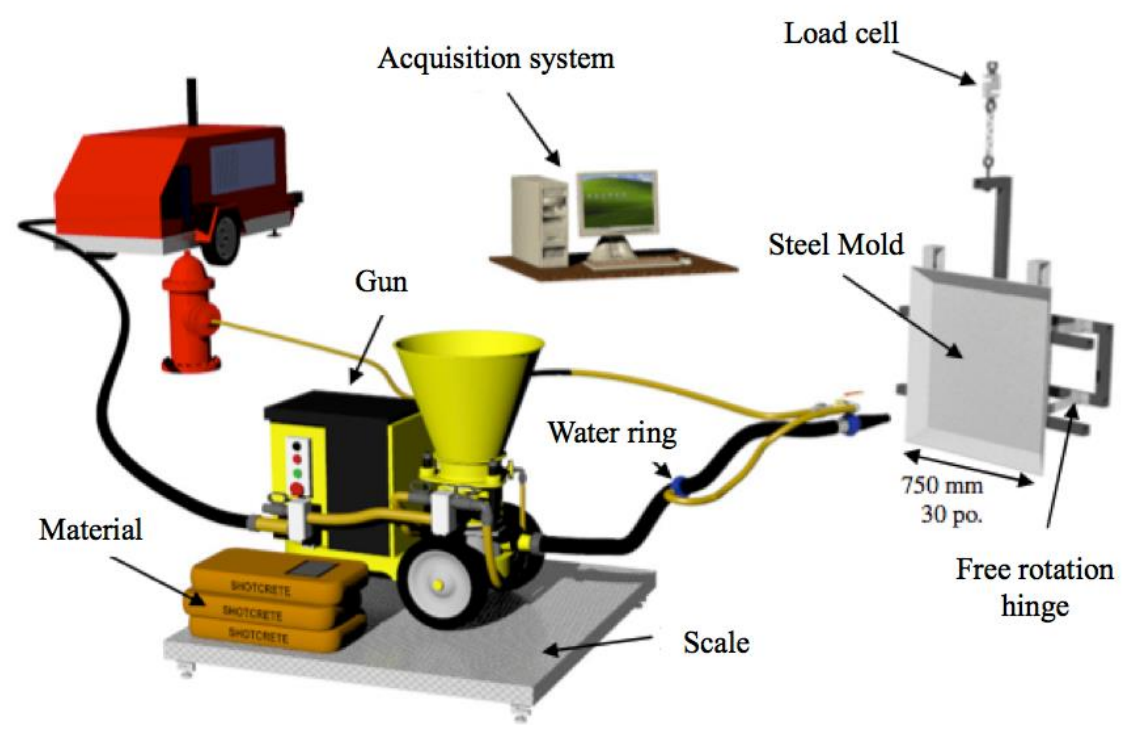

Figure 3 Schematic of the electronic acquisition system

Prior to the shotcreting operation, $780 \mathrm{~kg}$ of dry shotcrete material was pre-weighted and pre-blended to allow for the production of the various panels and samples needed for testing. Table 3 shows the dry proportion of the pre-blended material.

\section{Table 3 Dry proportion of sprayed mixture}

\begin{tabular}{ccc}
\hline $\begin{array}{c}\text { Ternary binder } \\
\text { (\%) }\end{array}$ & \multicolumn{2}{c}{ Aggregate (\%) } \\
\hline 19.0 & Sand & Rock \\
\hline
\end{tabular}

To correctly assess the strength development of the ternary mixture, compressive strength test were conducted. Early age compressive strength tests (up to $3 \mathrm{~h}$ ) were conducting using beam specimen. These beam specimens are sprayed in steel mould to realise end beam test (Heere \& Morgan 2002), which is a common test in the mining industry. Figure 4 shows the setup used to perform the test and an actual specimen tested.

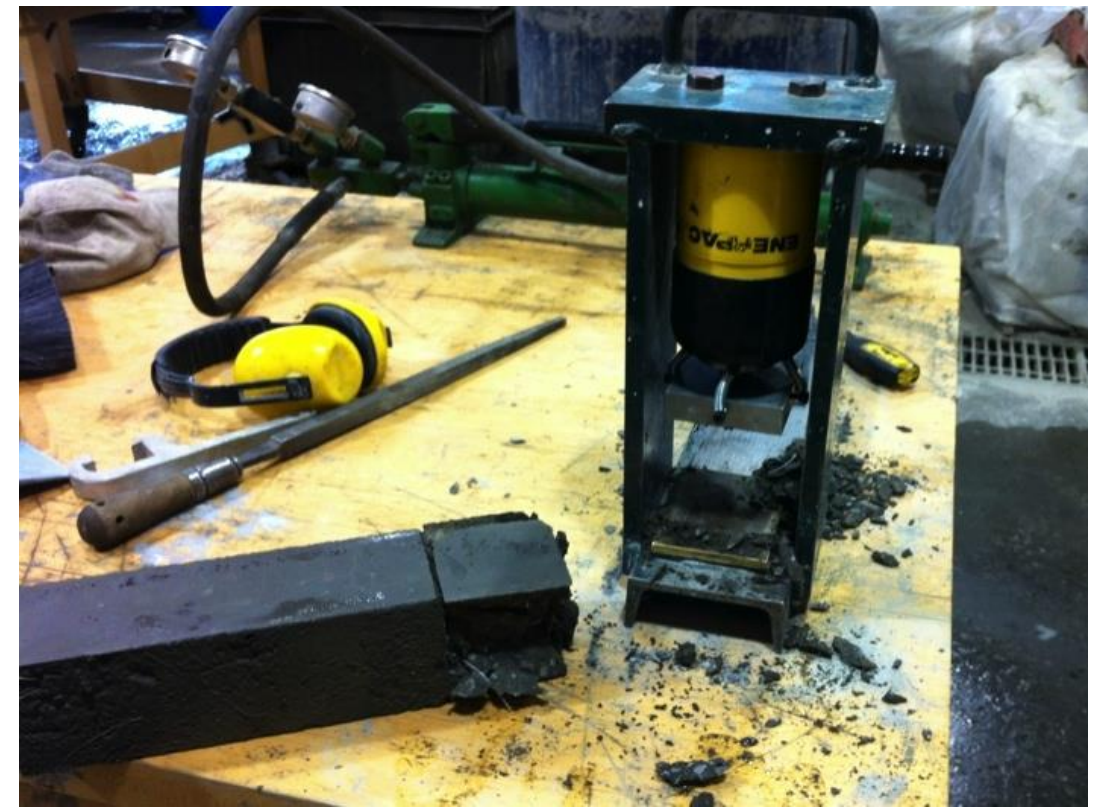

Figure 4 End beam test apparatus 
To evaluate compressive strength after $3 \mathrm{~h}, 75 \mathrm{~mm}(3 \mathrm{in})$ diameter cores were extracted from test panel (ASTM International 2003, 2005). Figure 5 shows the different test panels ready for shotcreting in the rebound chamber in the shotcrete laboratory.

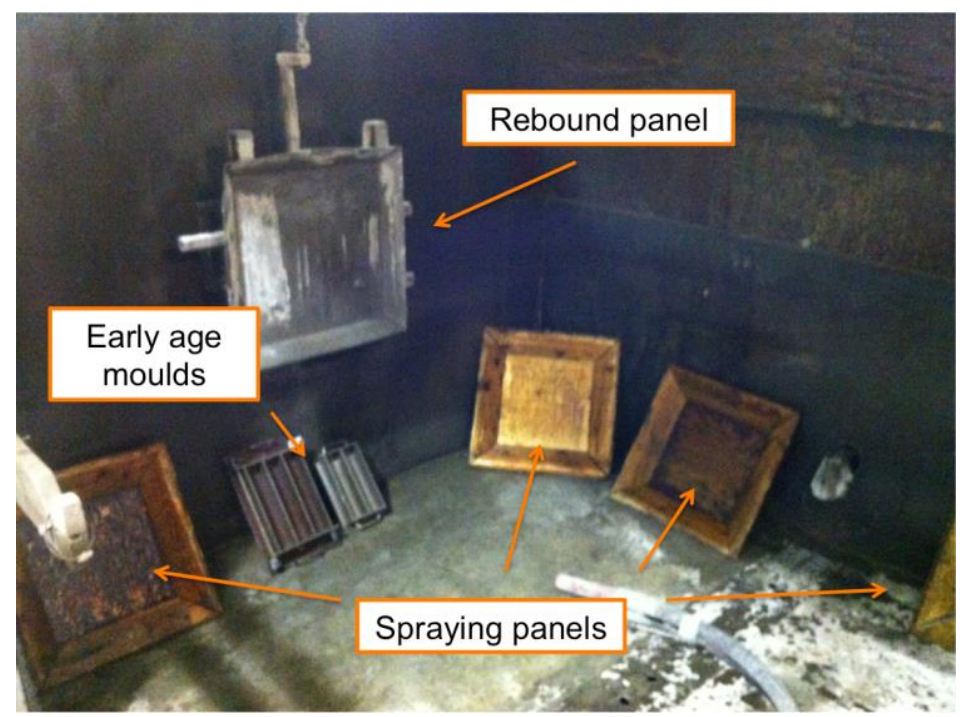

\section{Figure 5 Rebound chamber before spraying}

\section{$3 \quad$ Results}

\subsection{Phase 1 - results}

To obtain an accurate representation of the expansion pattern of these types of ternary binder, over 49 different mixtures were tested. The fast setting nature of the OPC-CAC-C\$ binder ended up requiring the assistance of three persons to cast the cubes. Doing otherwise resulted in the setting of the mixture prior to proper placement. Initial setting of less than 5 minutes has been observed on some mixture. Figure 6 presents all the mixtures tested in Phase 1. Figure 7 presents the wide range of expansion observed for the unstable mixtures.

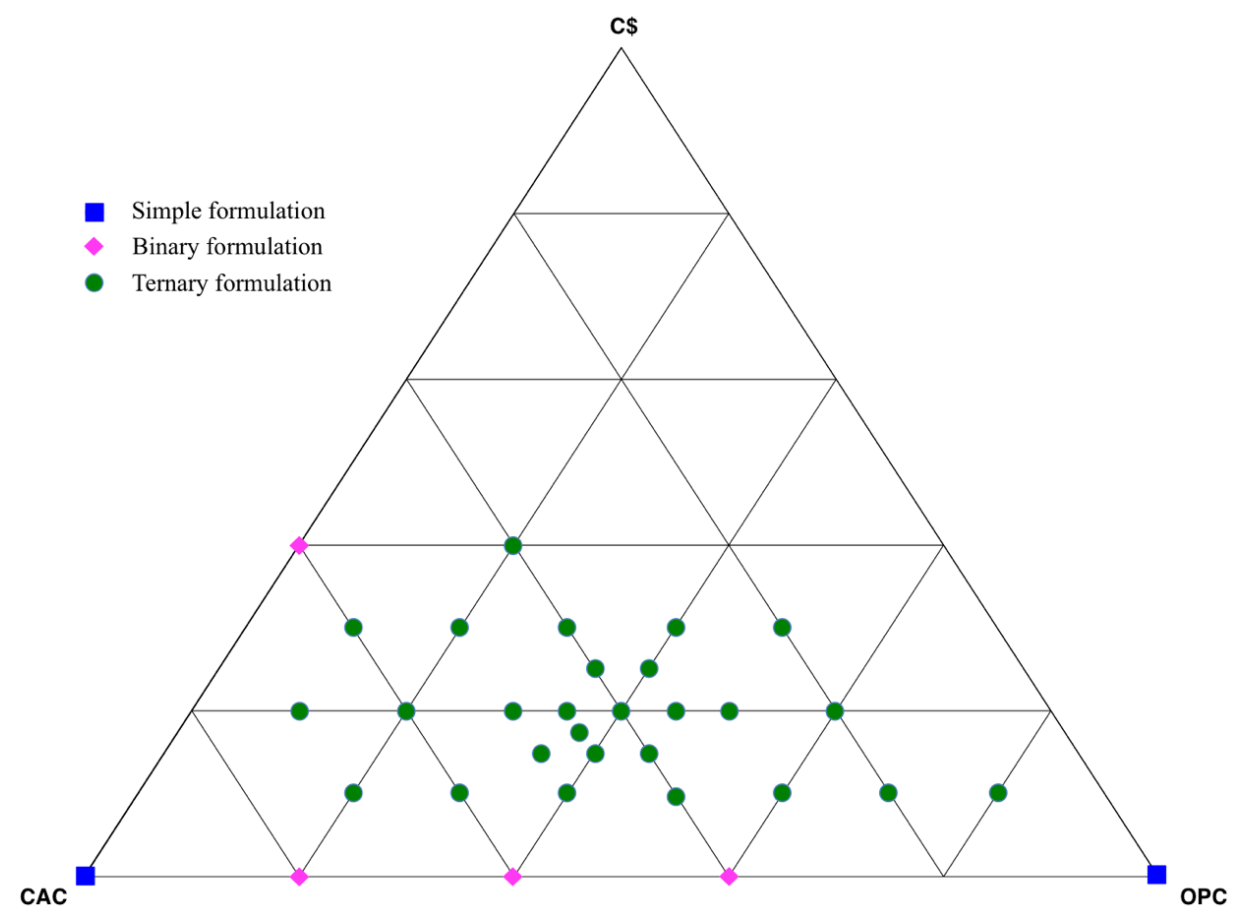

Figure 6 Expansion limit found in this study 


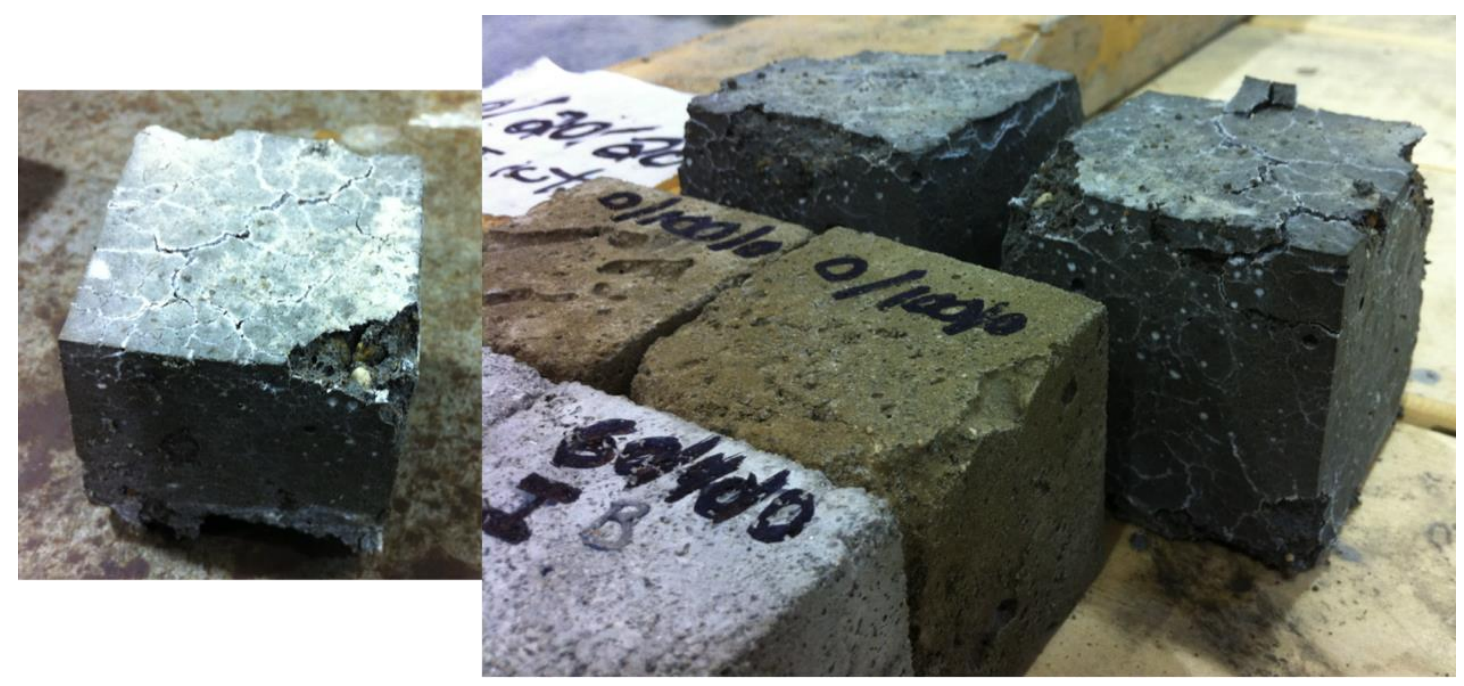

(a)

(b)

Figure 7 (a) expansion of a mixture close to the expansion line; and (b) expansive mixture compare to a stable mixture

The line leading to expansion is not a straight line because of the variability in the OPC, CAC and C\$ oxide in the binders. Because of this difference and the very sensitive nature of the expansion, a strait and clear expansion limit cannot be identified. This means that with any composition change in any of the three component of the binder, this limit must be investigated again. Doing otherwise may lead to catastrophic expansion of the mixture.

It should be note that the limit observed is very similar to what was observed by Lamberet (Lamberet 2005) with a minor difference in the C\$ content leading to expansion on the CAC side of the line. This is most likely due to the difference between the material used in Europe and Canada. For instance, a minor change in sulphate contents $\left(\mathrm{SO}_{3}\right)$ can have an important change in the mixture stability.

Based on the results from Phase 1, a non-expansive mixture was chosen for the shotcreting operations. The results and discussion on this selection can be found in previous work (Lemay et al. 2014).

\subsection{Phase 2 - placement and adhesion}

The first goal of this shotcreting session is to establish whether the new type of binder allows for proper shooting and placement of dry-mix shotcrete. Using the standard equipment described above, the shotcreting was a success. Indeed, the use of the hydromix nozzle was efficient in reducing dust emission and no plugging was observed; dust and rebound were similar to those obtained with traditional dry-mix shotcrete mixture design. Later coring of the test panels confirms the homogeneity of the in-place material.

Overall, the material shot very well and allow the placement on vertical surfaces without the need of accelerator; the in-place mixture showed sufficient cohesion and adhesion to stay in place with more than $125 \mathrm{~mm}$ ( 5 in) thickness while presenting rebound losses of approximately $20 \%$.

\subsection{Phase 2 - compressive strength}

The spraying was successful using standard dry-mix shotcrete equipment. Particularly, the use of a

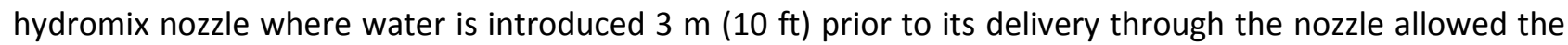
production of homogeneous good quality shotcrete with no clogging in the equipment. Table 3 presents the average compressive strength obtained using the end beam test (Figure 4) and the average compressive strength using three cores taken from panels. 
Table 4 Average compressive strength

\begin{tabular}{cccccccc}
\hline \multirow{2}{*}{ Specimens } & \multicolumn{8}{c}{ Compressive strength (MPa) } \\
& $1 \mathrm{~h}$ & $2 \mathrm{~h}$ & $3 \mathrm{~h}$ & $6 \mathrm{~h}$ & $1 \mathrm{~d}$ & $7 \mathrm{~d}$ & $28 \mathrm{~d}$ \\
\hline Prisms & 12.9 & 24.9 & 29.6 & - & - & - & - \\
Cores & - & - & 35.6 & 47.6 & 54.6 & 51.9 & 52.1 \\
\hline
\end{tabular}

The results presented in Table 4 are actually quite impressive and are deemed a success for the mining and tunnelling industry; indeed, typical early age and compressive strength obtained with ordinary Portland cements based mix design and set accelerators are usually around 3-4 MPa. Compressive strength over $30 \mathrm{MPa}$ at $3 \mathrm{~h}$ with $28 \mathrm{~d}$ compressive strength of some $50 \mathrm{MPa}$ are extremely promising. On the other hand, the $1 \mathrm{~h}$ results also show very interesting potential for emergency response. Structural damages caused by fire in tunnels or by natural disasters (e.g. flooding or earthquakes) on essential structures could be very rapidly be alleviated using such a mix design in combination with the dry-mix shotcrete application method. In fact, although not measured because of its rapid onset, the setting time of the mixture used is very short ( $<10$ minutes) which translates most probably in a few megapascals of compressive strength with minutes of its placement.

Obviously, the use of dry mix shotcrete represents an extremely well adapted method for placing such potent mixtures. Indeed, the fact that all of the dry materials are conveyed with air through the hose to the nozzle where water is added gives a very short contact time between the water and the cementing materials before it is sprayed onto the surface. By using pre-blended bulk bags that can be stored for long period of time, it becomes easy to have concrete material ready in case of emergency. Combined with the very simple mobilisation of dry-mix shotcrete and absence of a need for formwork, a fast and reliable system could be obtained.

\section{$4 \quad$ Conclusion}

The objective of this research project was to produce a dry mix shotcrete material offering a very rapid strength development. This was successfully achieved using standard shotcreting equipment.

While normal non-accelerated shotcrete usually need a couple of hour before showing any compressive strength, it was possible to walk on the shotcrete developed after 10 minutes. The very rapid hardening provides extremely high early compressive strength (12 $\mathrm{MPa}$ at $1 \mathrm{~h}$ ) showing very interesting potential for emergency response. Structural damages caused by fire in tunnels or by natural disasters on essential structures could be very rapidly alleviated using such a mix design in combination with the dry-mix shotcrete application method. Along with pre-blended bulk bags and combined with the ease of mobilisation of dry-mix shotcrete equipment, a fast and reliable system could be obtained for rapid structural emergency response.

The next step toward the acceptance of this new kind of binder is field testing. While showing a traditional comportment in the laboratory, extensive testing on the field must be done before it is use on a large scale.

\section{Acknowledgement}

The authors would like to thank the Centre de Recherche sur les Infrastructures en Béton (CRIB) for the funding of this research project.

\section{References}

American Concrete Institute 2005, ACl-506.R: Guide to Shotcrete, ACl, Farmington Hills.

American Concrete Institute 2009, CP-60(09): Craftsman Workbook for ACl Certification of Shotcrete Nozzleman, ACl, Farmington Hills.

ASTM International 2003, C1140: Standard Practice for Preparing and Testing Specimens from Shotcrete Test Panels, ASTM International, West Conshohocken. 
ASTM International 2005, C1604: Standard Test Method for Obtaining and Testing Drilled Cores of Shotcrete, ASTM International, West Conshohocken.

Heere, R, Morgan, DR 2002, 'Determination of Early-Age Compressive Strength of Shotcrete', American Shotcrete Association Magazine, Spring issue, pp. 28-31.

Lamberet, S 2005, 'Durability of Ternary Binders Based on Portland Cement, Calcium Aluminate Cement and Calcium Sulfate', PhD thesis, École Polytechnique Fédérale de Lausanne, Lausanne.

Lemay, J-D 2013, 'Développement de Béton Projeté à Ultra-Haute Résistance Initiale', M. Sc. thesis, Université Laval, Québec.

Lemay, J-D, Jolin, M \& Gagné, R 2014, 'Ultra High Early Strength Shotcrete: New Binder Composition Approach', Proceedings of the International Conference on Calcium Aluminates, in C Fentiman, R Mangabhai \& K Scrivener (eds), HIS BRE Press, Garston.

Neville, AM 2008, Properties of Concrete, 4th edn, Pearson Prentice Hall, UK.

Prudêncio Jr., LR 1998, 'Accelerating Admixture for Shotcrete', Cement and Concrete Composites, vol. 20, pp. 213-219. 
